\title{
Effectiveness of interventions to reduce aggression and injuries among ice hockey players: a systematic review
}

\author{
Michael D. Cusimano MD PhD, Sofia Nastis BSc, Laura Zuccaro BHSC
}

\begin{abstract}
- Abstract
Background: The increasing incidence of injuries related to playing ice hockey is an important public health issue. We conducted a systematic review to evaluate the effectiveness of interventions designed to reduce injuries related to aggressive acts in ice hockey.
\end{abstract}

Methods: We identified relevant articles by searching electronic databases from their inception through July 2012, by using Internet search engines, and by manually searching sports medicine journals, the book series Safety in Ice Hockey and reference lists of included articles. We included studies that evaluated interventions to reduce aggression-related injuries and reported ratings of aggressive behaviour or rates of penalties or injuries.

Results: We identified 18 eligible studies. Most involved players in minor hockey leagues. Of 13 studies that evaluated changes in mandatory rules intended to lessen aggres- sion (most commonly the restriction of bodychecking), 11 observed a reduction in penalty or injury rates associated with rule changes, and 9 of these showed a statistically significant decrease. The mean number of penalties decreased by 1.2-5.9 per game, and injury rates decreased 3 - to 12 -fold. All 3 studies of educational interventions showed a reduction in penalty rates, but they were not powered or designed to show a change in injury rates. In 2 studies of cognitive behavioural interventions, reductions in aggressive behaviours were observed.

Interpretation: Changes to mandatory rules were associated with reductions in penalties for aggressive acts and in injuries related to aggression among ice hockey players. Effects of educational and cognitive behavioural interventions on injury rates are less clear. Welldesigned studies of multifaceted strategies that combine such approaches are required.
$\mathrm{O}$ ver the last 15 years, the incidence of brain and spinal cord injuries among ice hockey players has increased. ${ }^{1} \mathrm{~A}$ recent study involving players in junior leagues found that, in the 2009/10 hockey season, the incidence of game-related concussions was 7 times higher than the highest rate previously reported in 1998/99. ${ }^{2}$ Brain injuries frequently result from aggressive bodychecking ${ }^{3}$ and account for $15 \%$ of injuries among players $9-16$ years of age. ${ }^{4,5}$ In a study of a community-based hockey program involving boys aged $9-15$ years, hostile aggressive acts, which have an intention to do harm, ${ }^{6}$ were the primary cause of injury in one-third of games in which an injury resulted. ${ }^{7}$ Among high school students in Minnesota who played varsity ice hockey, those who played to relieve aggression were 4 times more likely than other players to experience a concussion. ${ }^{8}$ These findings highlight the association between aggressive behaviour and injury in ice hockey. However, little is known about what can be done to reduce this behaviour to create a safer environment for the sport.

Existing reviews about reducing injury in sport have primarily assessed equipment or risk factors associated with injury. ${ }^{9-11}$ Recent systematic reviews highlighted the risks of bodychecking and renewed calls for policies to disallow bodychecking among youth playing ice hockey. ${ }^{3,12}$ We conducted a systematic review to assess the effectiveness of interventions designed to reduce aggressive acts and related injuries among ice hockey players. We were particularly interested in evaluating the effectiveness of rule changes, educational interventions and behavioural modification in reducing aggressive acts and related injuries.

\section{Methods}

\section{Data sources}

We searched 8 electronic databases for potentially relevant articles published from the time
Competing interests: None declared.

This article has been peer reviewed.

Correspondence to: Michael D. Cusimano, injuryprevention@smh.ca

CMAJ 2013. DOI:10.1503 /cmaj.112017 
of the database's inception through July 2012: MEDLINE (using the search engines Ovid [from 1950] and PubMed [from 1948]), Embase (from 1980), CINAHL (from 1981), Journals @ Scholars Portal (from 1960), the Cochrane Library (from 1980), PsycINFO (from 1987) and Web of Science (from 1976). For each search, we used a combination of Medical Subject Headings (MeSH) and key words, including "hockey," "ice hockey," "aggression," "violence," "anger," "injury," "wounds and injuries," "injury prevention," "prevention studies," "intervention," "intervention studies," "prevention," "reducing," "protection" and "education." (Details of the search strategy are provided in Appendix 1, available at www.cmaj.ca/lookup /suppl/doi:10.1503/cmaj.112017/-/DC1). Search terms were modified based on search results to generate increasingly inclusive sets of potentially relevant articles. We did not restrict these searches by language, publication year or publication status.

We also used the Internet search engines Yahoo!, Google, Google Scholar and Dogpile, with the same search terms as those listed above. We manually searched for related articles in 4 sports medicine journals (American Journal of Sports Medicine, British Journal of Sports Medi-

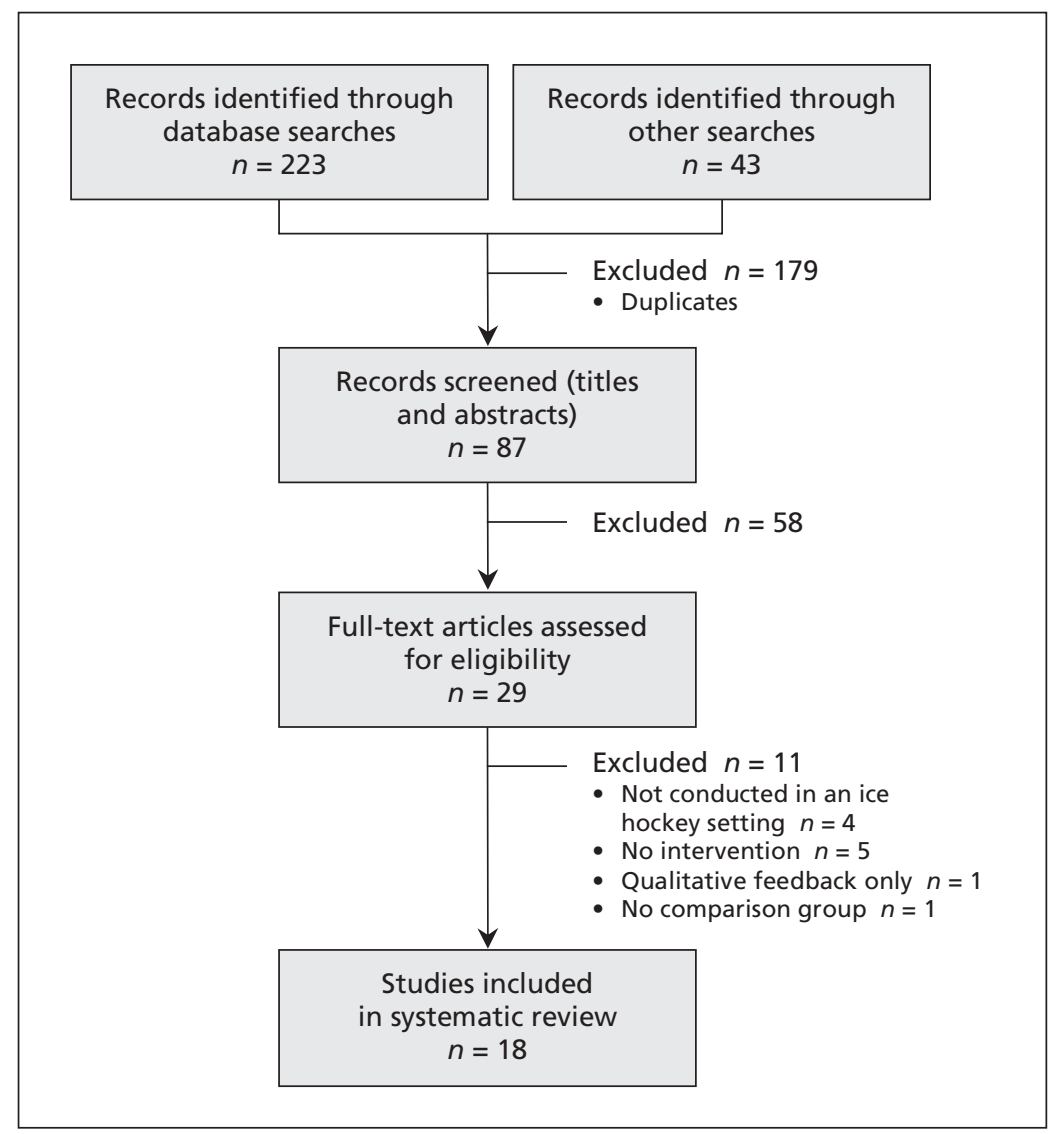

Figure 1: Selection of articles for inclusion in the systematic review. cine, Injury Prevention, and Sports Medicine, all of which commonly publish articles related to ice hockey and injury prevention) from 2000 to 2010; all 5 volumes of Safety in Ice Hockey, ${ }^{13-17}$ and the bibliographies of all included studies. We reviewed the titles and abstracts of potentially relevant articles to identify studies that met our selection criteria (Figure 1).

\section{Study selection}

We included studies of interventions applied directly to the hockey coaches or players that attempted to reduce aggressive behaviours in ice hockey, had a comparison group (cross-sectional, case-control, cohort, before-after, quasiexperimental and randomized controlled trial designs were all considered), and measured injuries, penalties or ratings of aggressive behaviour as outcomes. We excluded studies that applied to other types of hockey, involved only the use of protective equipment or were not conducted in an ice hockey setting.

\section{Data extraction and synthesis}

Two of us (S.N. and L.Z.) independently reviewed the articles of the included studies and extracted the data; the third author (M.D.C.) confirmed that the extraction of data was complete. We obtained data on the study design, the study population, the hypothesis or research question, the outcome measures, the study methods, the statistical analyses, the results and the conclusions. We assessed the methodologic quality of each study based on a checklist created by Downs and Black. ${ }^{18}$

The individual studies had considerable heterogeneity and varied by interventions, outcome measures and definitions of exposure. This heterogeneity precluded the ability to perform a meta-analysis.

\section{Results}

\section{Included studies}

Of the 29 full-text manuscripts retrieved for preliminary consideration, 18 were selected for inclusion in our review. We excluded 11 articles because the study did not assess aggression or injury related to players in an actual ice hockey setting $(n=4)$, there was no intervention $(n=5)$, only qualitative feedback from coaches was reported, or the study had no comparison group. (The citations of the excluded studies are provided in Appendix 2, available at www.cmaj.ca /lookup/suppl/doi:10.1503/cmaj.112017/-/DC1).

Of the 18 included studies, 13 assessed the effectiveness of changes in mandatory league rules, ${ }^{19-31} 3$ assessed the effectiveness of educational interventions, ${ }^{32-34}$ and 2 assessed the effec- 
tiveness of psychosocial interventions. ${ }^{35,36}$ Thirteen of the studies included youth players in minor leagues. One study involved players in Canada and the United States, 13 studies were completed solely in Canada, and 4 were completed in the United States. Characteristics of the included studies are summarized in Table 1.

\section{Quality assessment}

Details of our assessment of the methodologic quality of the studies based on the criteria of Downs and Black ${ }^{18}$ are provided in Appendix 3 (available at www.cmaj.ca/lookup/suppl/doi :10.1503/cmaj.112017/-/DC1). In brief, several studies ${ }^{19-22,24,26,28-31,34}$ drew on large samples, such as all hospital visits in multiple Canadian provinces. In some studies, confounding variables were difficult to control because of their retrospective or observational nature, ${ }^{25,26,30}$ and only one of the studies was randomized. ${ }^{33}$ No studies looked at broader outcomes such as the effects of injury on participation rates in hockey or advancement of players to higher or elite levels of play.

\section{Effect of interventions}

The effects of the interventions on aggressive acts and related injuries are summarized in Table 2.

\section{Rule changes}

Thirteen studies evaluated changes in mandatory rules intended to curb aggressive behaviour and subsequent injury. ${ }^{19-31}$ Three studies examined the Fair Play Program. ${ }^{20,21,23}$ This program includes sportsmanship as a component of the final standings, adapted from an experimental program created by Edmond Vaz. ${ }^{37}$ Points are awarded to teams at the end of every season or tournament for staying below a pre-established limit of team penalties per game. ${ }^{21}$ Nine studies investigated bodychecking rules..$^{19,22,24,25,27-31}$ The remaining study examined legal punishment for aggressive illegal acts in professional hockey ${ }^{26}$

The 3 studies of the Fair Play Program noted an overall decrease in the number or severity of penalties, ${ }^{20,21,23}$ and one also reported a decrease in injury rates. ${ }^{21}$

Most of the 9 studies evaluating the enforcement of rules prohibiting bodychecking observed reductions in penalties, injuries or both, and in many studies these differences were statistically significant. Seven of the 9 studies showed decreased injury rates. . $922,2,2,25,27,28,30$ Typical of this group of studies, Regnier and colleagues ${ }^{19}$ noted more penalties in games in which bodychecking was allowed, along with a higher risk of serious injury among Peewee players (age 11-12 years). Macpherson and colleague $^{24}$ found that injury rates in boys' minor hockey in Ontario and Quebec were higher in leagues in which bodychecking was allowed than in leagues in which it was not allowed. The players in leagues that allowed bodychecking were also more likely to experience a concussion or fracture. Among older players (age 1415 years), all of whom were in leagues that allowed bodychecking, checking-related injuries were more common among those who had previous experience with it (Ontario leagues) than among those introduced to bodychecking for the first time (Quebec leagues); this difference suggests a protective effect of delaying the introduction of bodychecking. On the contrary, Kukaswadia and colleagues' retrospective cohort study noted a beneficial effect of introducing bodychecking at an earlier age, but it excluded a large number of possible cases to control for confounding variables. ${ }^{29}$

One study examined the impact of legal punishment on the frequency of aggressive behaviour across the National Hockey League (NHL) ${ }^{26}$ After the Bertuzzi incident (a widely publicized incident of highly aggressive and injurious behaviour for which player Todd Bertuzzi received a high-profile legal charge), there was an insignificant reduction in the overall frequency of aggressive behaviour but a significant decrease in specific acts of aggression (fighting and game misconduct infractions).

\section{Educational interventions}

All 3 studies that evaluated the effectiveness of educational interventions showed a reduction in penalties, but they were not powered or designed to show a change in injury rates. ${ }^{32-34}$

In the only randomized controlled trial included in our review, Cook and colleagues ${ }^{33}$ evaluated the effectiveness of ThinkFirst Canada's Smart Hockey video, which encourages respectful play to avoid injury and educates players and coaches about the diagnosis and treatment of concussion. This small study showed a decrease in the number of bodychecking-related penalties and the occurrence of aggressive and negligent behaviour, but it did not measure injury rates.

In a before-after study, Trudel and colleagues evaluated an intervention from the 1980s that introduced coaches to methods for properly teaching hockey skills through both video and training sessions. ${ }^{32}$ The authors reported a significant decrease in the number of penalties per game in only 1 of the 4 leagues that adopted the strategy and showed that the proportion of major injuries related to body- 


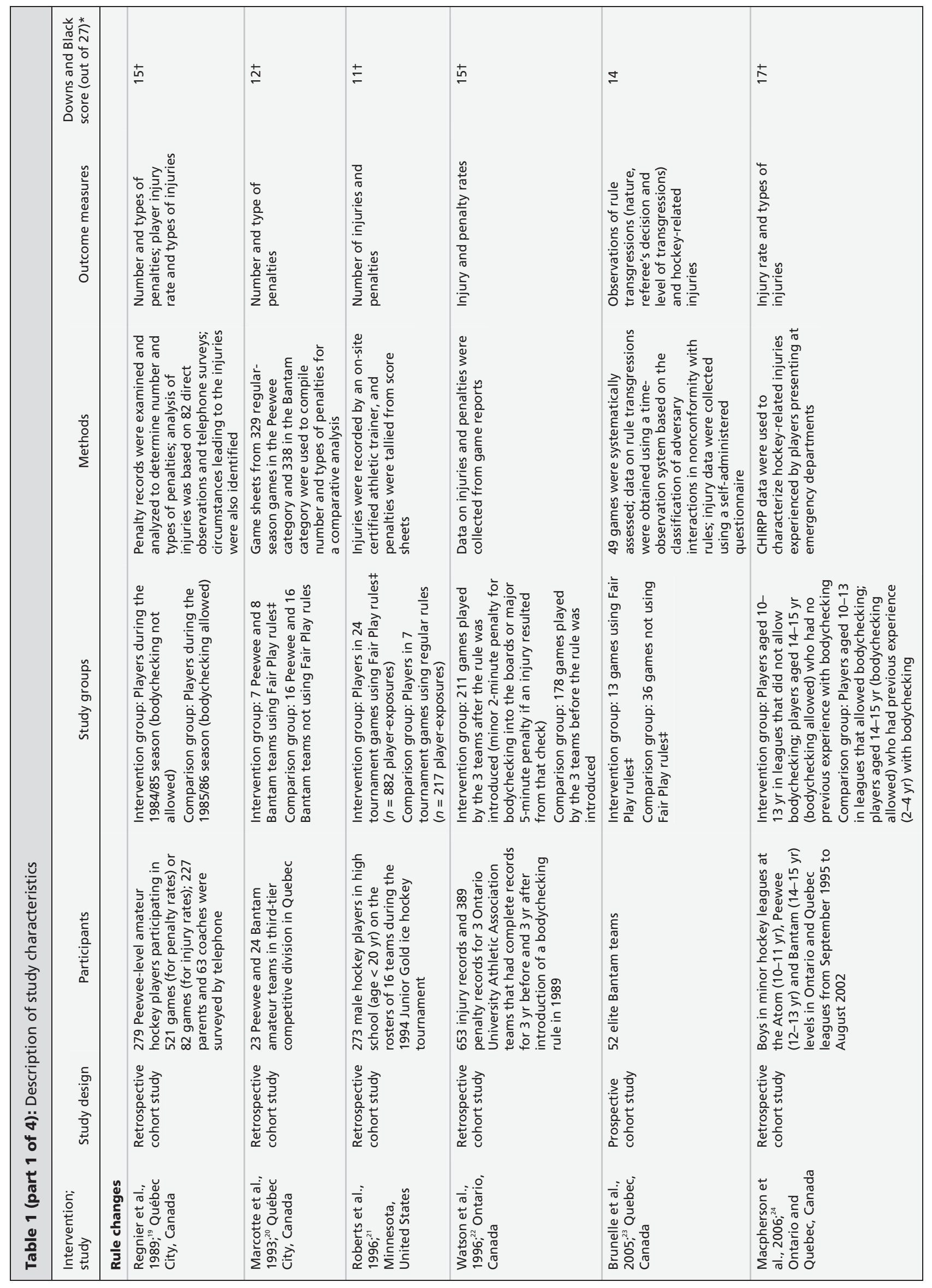




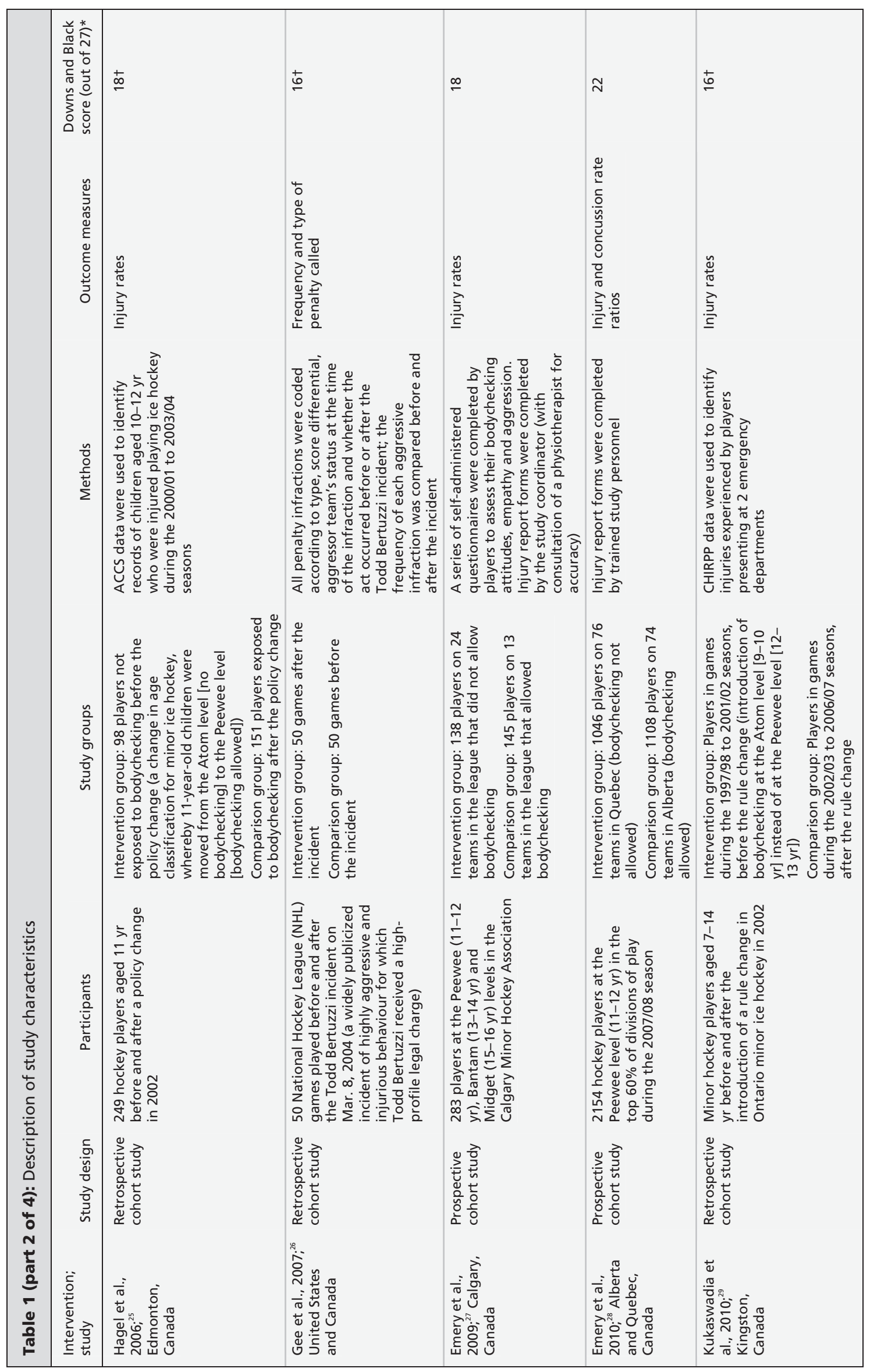




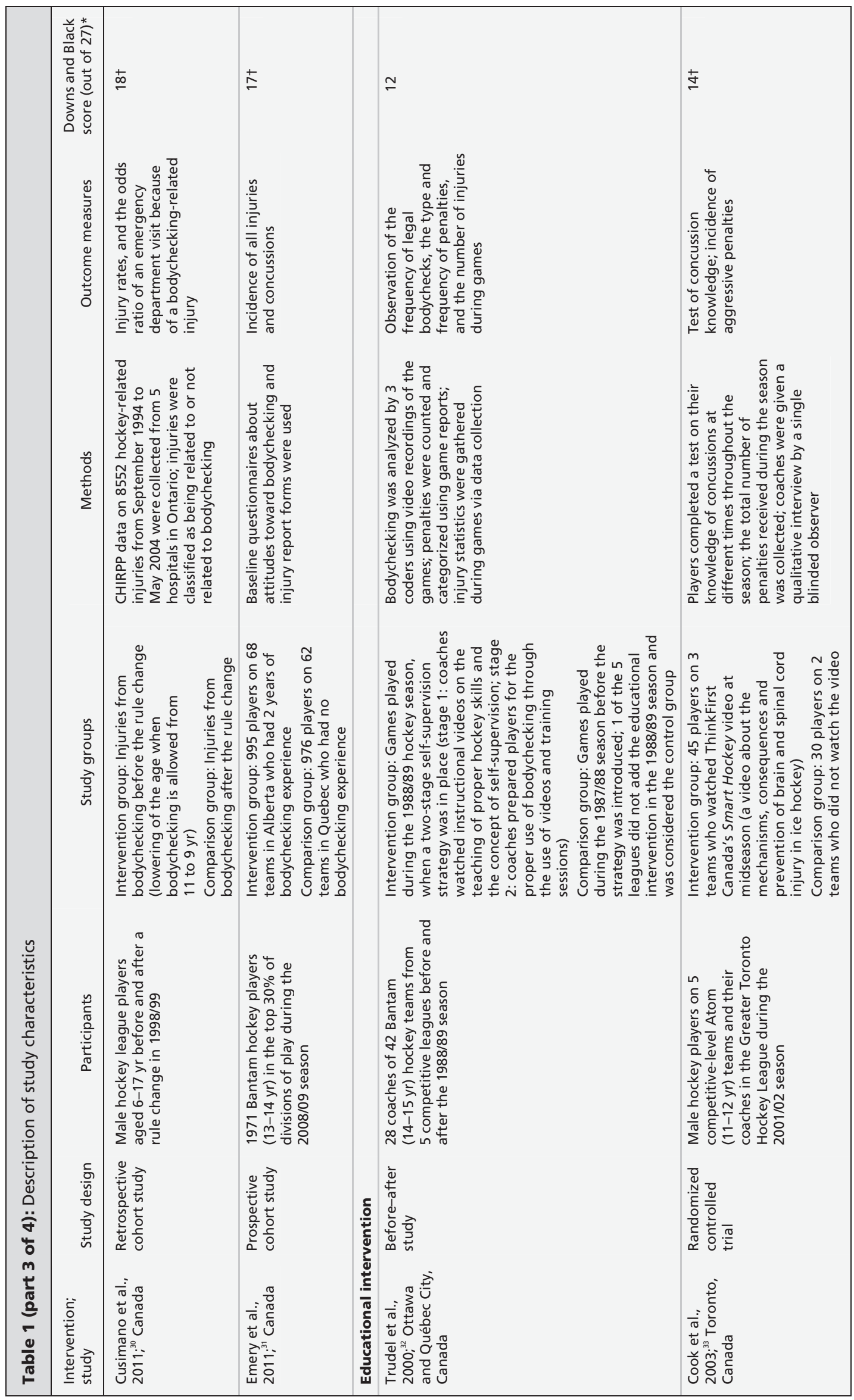




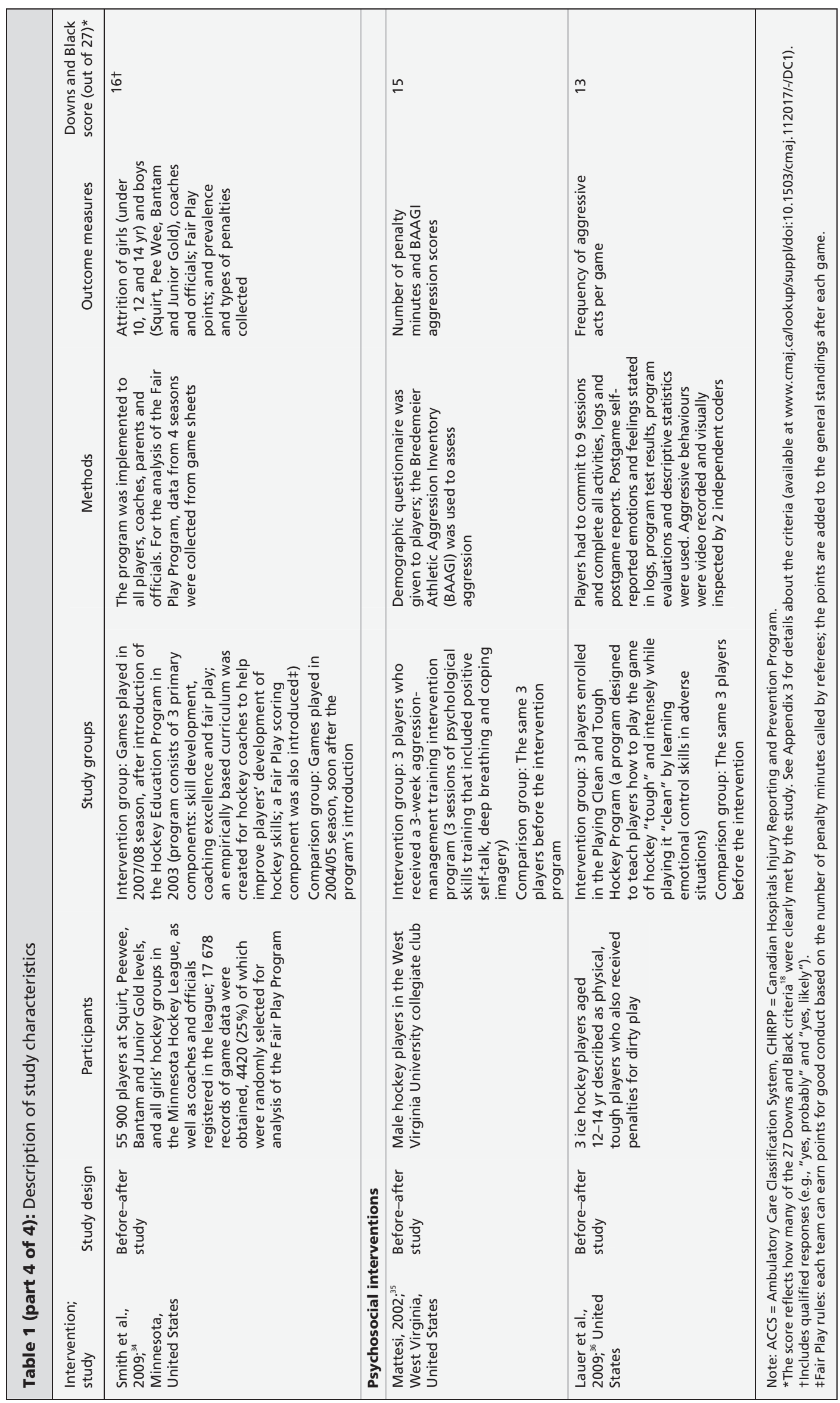


Table 2 (part 1 of 3): Description of study outcomes, by type of intervention

$\begin{array}{lll}\begin{array}{l}\text { Intervention; } \\ \text { study }\end{array} \quad \text { Effect on penalties for aggressive acts } & \text { Effect on injury rate }\end{array}$

\section{Rule changes}

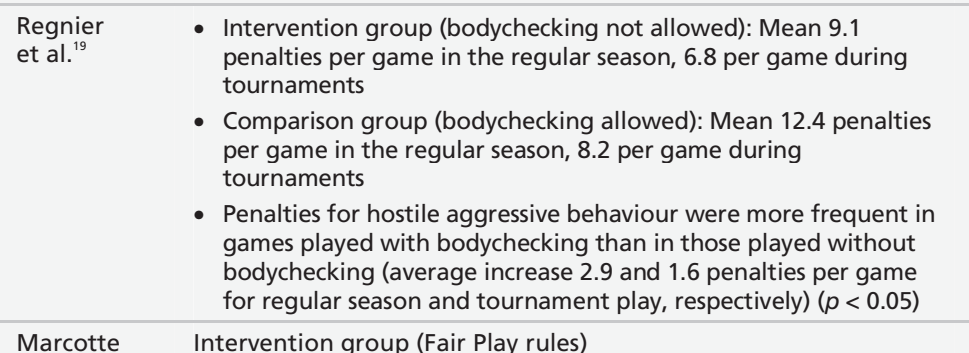

et al. $^{20} \quad$ - Peewee league: Mean 4.5 penalties per team per game, and 1.2

- Intervention group: 7 injuries (1 fracture) in 263 games

- Comparison group: 26 injuries (14 fractures) in 315 games; 1 fracture per 22.5 games; injury rate was 12 times greater than in intervention group ( $p$ value not reported)

- $88 \%$ of all fractures were related to bodychecking ( $p$ value not reported)

Not reported major penalties per team per season; 1 fewer penalty per game on average than in comparison group ( $p$ value not reported)

- Bantam league: Mean 7.8 penalties per team per game; fewer penalties than in comparison group ( $p$ value not reported)

- Bantam league: 30\% fewer major penalties and 25\% fewer game suspensions than in comparison group ( $p$ value not reported) Comparison group (regular play)

- Peewee league: Mean 5.7 penalties per team per game, and 6.4 major penalties per team per season

- Bantam league: Mean 8.4 penalties per team per game

\begin{tabular}{|l|l|}
\hline $\begin{array}{l}\text { Roberts } \\
\text { et al. }{ }^{21}\end{array}$ & - Intervention group (Fair Play rules): 7.1 penalties per game \\
& - Comparison group (regular play): 13.0 penalties per game; \\
& there were 4 times more penalties related to rough play than \\
& in the intervention group ( $p$ value not reported)
\end{tabular}

\begin{tabular}{|c|c|}
\hline $\begin{array}{l}\text { Watson } \\
\text { et al. }\end{array}$ & $\begin{array}{l}\text { - Intervention group: } 669 \text { body-contact penalties per game and } \\
498 \text { stick-related penalties per game after introduction of rule } \\
\text { disallowing checking from behind } \\
\text { - Comparison group: } 762 \text { body-contact penalties per game and } \\
695 \text { stick-related penalties per game before introduction of } \\
\text { the rule } \\
\text { - Significantly lower rates for body-contact and stick-related } \\
\text { penalties after introduction of the rule }(p<0.001)\end{array}$ \\
\hline $\begin{array}{l}\text { Brunelle } \\
\text { et al. }\end{array}$ & $\begin{array}{l}\text { - Intervention group (Fair Play rules): } 3195 \text { transgressions recorded } \\
\text { - Comparison group (regular play): } 8076 \text { transgressions recorded } \\
\text { - Significantly fewer penalties per game in the intervention } \\
\text { group }(p<0.01)\end{array}$ \\
\hline
\end{tabular}

Macpherson Not reported

et al. ${ }^{24}$ there were 4 times more penalties related to rough play than in the intervention group ( $p$ value not reported)

- Intervention group: 5.7 notable injuries (> $1 \mathrm{~d}$ of play lost, facial laceration or concussion) per 1000 player-exposures

- Comparison group: 27.6 notable injuries per 1000 playerexposures

- Ratio of notable injuries per 1000 player-exposures in regular games to such injuries in games following Fair Play rules was nearly 5:1 ( $p$ value not reported)

- Intervention group: 16 head/neck injuries per 1000 playergames and 16 back injuries per 1000 player-games

- Comparison group: 26 head/neck injuries per 1000 player-games and 21 back injuries per 1000 player-games

- Rates of head/neck and back injuries decreased significantly after introduction of the rule $(p<0.001)$

Not reported

- Intervention group: 1730 (37\%) of 4736 hockey-related injuries were in Quebec, where bodychecking was not allowed until Bantam level (14-15 yr)

- Comparison group: 3006 (63\%) of 4736 hockey-related injuries were in Ontario, where bodychecking was introduced at the Peewee level (12-13 yr), and at the Atom level in competitive leagues (10-11 yr) in certain jurisdictions

- Most of the injuries (3618 [76.4\%]) occurred in games where bodychecking was allowed

- Players aged 10-13 yr in leagues that allowed bodychecking were at increased risk of a bodychecking-related injury (OR 2.65, 95\% Cl 2.21-3.18); they were also at increased risk of concussion (OR $1.53,95 \% \mathrm{Cl} 0.93-2.52$ ) or possibly a fracture (OR $1.20,95 \%$ Cl 1.00-1.47)

\begin{tabular}{l|l} 
Hagel & Not reported \\
et al. $^{25}$ &
\end{tabular}

- Intervention group (bodychecking not allowed): 40.6 injuries per 1000 players; $33(40.2 \%)$ of players had severe injuries

- Comparison group (bodychecking allowed): 85.5 per 1000 players; $77(51.0 \%)$ of players had severe injuries

- The overall injury rate was significantly greater in the comparison group than in the intervention group (rate ratio $1.9,95 \% \mathrm{Cl} 1.4-2.6)$; the rate of severe injuries was more than 2 times greater in the comparison group (rate ratio $2.4,95 \%$ Cl 1.6-3.6) 
Table 2 (part 2 of 3): Description of study outcomes, by type of intervention

Intervention; study

Effect on penalties for aggressive acts
Gee et al. ${ }^{26}$ - Intervention group (after the Bertuzzi incident): Mean 5.2 aggressive infractions per game, 60 fighting infractions and 2 game-misconduct infractions

- Comparison group (before the incident): Mean 6.5 aggressive infractions per game, 91 fighting infractions, and 22 gamemisconduct infractions

- Slight but nonsignificant reduction in the frequency of aggressive behaviours after the incident $(p=0.3)$

- When individual acts of aggression (e.g., slashing, fighting) were examined independently, infractions for fighting and game misconduct significantly decreased after the incident $(p<0.05)$

Emery Not reported

et al. ${ }^{27}$

Emery Not reported

et al. ${ }^{28}$

Kukaswadia Not reported

et al. ${ }^{29}$

et al. $^{30}$

Not reported

Not reported

Emery

et al. ${ }^{31}$
- Intervention group (bodychecking not allowed): 1.37 injuries per 100 players per season ( $95 \% \mathrm{Cl} 0.17-4.89) ; 0.43$ injuries per 100 player-hours

- Comparison group (bodychecking allowed): 24.64 injuries per 100 players per season (95\% Cl 17.71-32.69); 3.16 injuries per 100 player-hours

- Relative risk of injury considering exposure-hours was 4.89 (95\% Cl 1.54-24.9) in the comparison group; however, attitudes toward bodychecking, empathy and aggression did not influence injury rates

- Intervention group (bodychecking not allowed): 91 injuries (23 concussions) reported during 82099 player exposure-hours

- Comparison group (bodychecking allowed): 241 injuries (78 concussions) reported during 85077 player exposure-hours

- The risk of any game-related injury and of concussion or other severe injury was 3 -fold greater ( $95 \% \mathrm{Cl} 2.31-4.60)$ in the comparison group than in the intervention group

- Intervention group: Before the rule change (to lower the age when bodychecking is introduced), the overall injury rate was 59.9 injuries per 1000 player-years (95\% Cl 55.4-64.4)

- Comparison group: After the rule change, the rate was 49.1 injuries per 1000 player-years $(95 \% \mathrm{Cl} 44.8-53.3)$

- Contrary to hypothesis, the overall injury rate decreased after the rule change ( $p$ value not reported); the overall rate of injury and concomitant neurotraumatic events did not increase ( $p$ value not reported)

- Intervention group: Before the rule change (to lower the age when bodychecking is introduced from the Peewee level to the Atom level), there were 1617 injuries overall (158 at the Atom level)

- Comparison group: After the rule change, there were 2843 injuries overall (243 at the Atom level)

- The odds of a bodychecking-related injury were significantly increased after the rule change in all divisions (OR 1.26, 95\% Cl 1.16-1.38) and at the Atom level (OR 2.20, 95\% Cl 1.70-2.84)

- Rates of injuries involving the head and neck (OR 1.52, 95\% Cl 1.26-1.84) and shoulder and arm (OR 1.18, 95\% Cl 1.04-1.35) increased most substantially

- Intervention group: 272 injuries (51 concussions) were reported during 96907 player-hours among players with previous bodychecking experience

- Comparison group: 244 injuries (49 concussions) were reported during 85464 player-hours among players without previous bodychecking experience

- The adjusted incidence rate ratio for game-related injury and concussion overall between players with previous bodychecking experience and those without it were as follows: injury overall 0.85 (95\% Cl 0.63-1.16), concussion overall 0.84 (95\% Cl 0.481.48 ) and injury resulting in more than $7 \mathrm{~d}$ of lost play 0.67 (95\% Cl 0.46-0.99)

- The rate of injury resulting in loss of on-ice time was reduced by $33 \%$ among players who had 2 years of bodychecking experience compared with players who had no previous bodychecking experience 
Table 2 (part 3 of 3): Description of study outcomes, by type of intervention

Intervention; study
Effect on penalties for aggressive acts
Effect on injury rate

\section{Educational interventions}

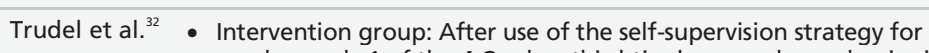
coaches, only 1 of the 4 Quebec third-tier leagues showed a significant reduction in the number of penalties per game (mean 9.0 before v. 8.1 after strategy; $p<0.001$ ). In terms of minor aggression penalties per game, this Quebec league showed a significant reduction (mean 5.9 before v. 5.4 after strategy; $p=0.02$ ); however, the Ottawa top-tier league showed a significant increase (mean 4.7 before v. 5.2 after strategy; $p=0.02$ ). The Quebec top-tier and Ottawa third-tier leagues showed no significant difference with the strategy

- Comparison group: The Franc-Sud third-tier Quebec league showed a significant decrease in the number of penalties per game the next year without using the strategy (mean 8.4 per game in $1987 / 88$ season v. 7.4 per game in $1988 / 89$ season; $p=0.009$ ); this team showed no significant change in the no. of minor aggression penalties per game

- Significant decrease in no. of penalties only in the Quebec third-tier league $(p<0.001)$

- Significant decrease in no. of minor aggressive penalties in the Quebec third-tier league $(p<0.02)$, but significant increase in Ottawa top-tier league $(p<0.02)$

Cook et al. ${ }^{33}$ - Intervention group (Smart Hockey video): The total no. of penalties per game did not change significantly among players after they watched the video ( $p$ value not reported); however, the mean $( \pm S E M)$ no. of penalties per 1000 player-hours decreased significantly $(p<0.05)$ for cross-checking penalties (from $23.7 \pm 1.3$ to $13.0 \pm 3.4$ ) and for penalties for checking from behind (from $38.4 \pm 3.7$ to $7.6 \pm 0.7$ )

- Comparison group (no video): The mean ( \pm SEM) no. of penalties per 1000 player-hours significantly $(p<0.05)$ decreased for interference penalties (from $50.0 \pm 5.0$ to $28.4 \pm 5.7$ ) and increased for holding penalties (from $12.5 \pm 2.5$ to $22.7 \pm 0.0$ )

- Overall, the total no. of penalties did not change significantly after watching the video ( $p$ value not reported)

Smith et al. $^{34}$ - Intervention group: In the $2007 / 08$ season, $4 \mathrm{yr}$ after HEP was implemented, the mean no. of penalties per 100 games was 310 tactical penalties, 205 minor penalties, 15 major penalties and 40 other penalties

- Comparison group: In the 2004/05 season, the first season after HEP was implemented, the mean no. of penalties per 100 games was 230 tactical penalties, 275 minor penalties, 80 major penalties and 140 other penalties

- The penalty rate decreased across all 4 seasons in all 4 sectors (tactical, minor, major, other) ( $p$ value not reported)

- The percentage of Fair Play points increased across all 4 seasons ( $p$ value not reported)

\section{Psychosocial interventions}

Mattesi $^{35} \quad$ - Intervention group: During the aggression-management training, the no. of penalty minutes per game was 1.67 for player $1,0.00$ for player 2 and 0.286 for player 3 ; after the intervention, the mean no. per game was 1.32 for player 1, 0.947 for player 2 and 1.0 for player 3

- Comparison group: Before the training, the mean no. of penalty minutes per game was 2.00 for player 1, 1.4 for player 2 and 1.18 for player 3

- Each player had a reduction in penalty minutes during and after the training; overall, the percentage of penalty minutes decreased after the training ( $p$ value not reported)

Lauer et al. $^{36} \quad$ - Intervention group: After the Playing Clean and Tough Hockey Program, the mean no. of aggressive acts per game was 3.92 for player 1, 3.90 for player 2 and 4.90 for player 3; for major aggressive acts, the mean no. per game was 1.00 for player $1,1.70$ for player 2 and 2.70 for player 3

- Comparison group: At baseline, the mean no. of aggressive acts per game was 4.00 for player 1, 4.42 for player 2 and 6.75 for player 3; for major aggressive acts, the mean no. per game was 1.25 for player 1, 2.25 for player 2 and 4.58 for player 3

- Overall, the ability to manage emotions increased and aggressivebehaviour variables decreased after the program for 2 of the 3 participants ( $p$ value not reported)
- Intervention group: Two leagues using the strategy experienced a mean decrease in the no. of minor injuries per game per team (Ottawa top tier: mean 0.6 before v. 0.5 after strategy; Ottawa third tier: mean 0.8 before v. 0.6 after strategy); the other 2 leagues using the strategy experienced a mean increase in minor injuries per game per team (Quebec top tier: mean 1.0 before v. 1.6 after strategy; Quebec third tier: mean 1.1 before v. 1.7 after strategy)

- Comparison group: The Franc-Sud third-tier league had a mean of 1.4 minor injuries per game in the 1988/89 season

- The proportion of major injuries related to bodychecking decreased from $75.0 \%$ to $68.7 \%$ after the strategy

- The strategy had no significant effect on the no. of minor injuries in all leagues

- Bodychecking was the main cause of all minor injuries during both seasons (in $46.2 \%$ of injuries in the $1987 / 88$ season and $46.7 \%$ in the $1988 / 89$ season)

\section{Not reported}

Not reported

\section{Not reported}

Not reported

Note: $\mathrm{Cl}=$ confidence interval, $\mathrm{HEP}=$ Hockey Education Program, OR = odds ratio, $\mathrm{SEM}=$ standard error of the mean. 
checking dropped from $75.0 \%$ to $68.7 \%$ after the intervention.

Smith and colleagues performed a beforeafter study of the Hockey Education Program the most multifaceted of the educational interventions designed to ensure youth players develop sportsmanship, skills and a Fair Play approach to the game. ${ }^{34}$ They found that the mean number of penalties per 100 games decreased in all 4 penalty sectors (tactical, minor, major and other) and that the percentage of Fair Play points increased throughout the 4 seasons studied. ${ }^{34}$

\section{Psychosocial interventions}

Two articles reported the effects of cognitive behavioural strategies used with individual hockey players to prevent their aggressive behaviour, but neither reported on the effects of such interventions on injuries. ${ }^{35,36}$ Mattesi reported an overall decrease in the percentage of penalty minutes after his aggression-management training was implemented among 3 players. ${ }^{35}$ In the study by Lauer and colleagues, ${ }^{36}$ the Playing Tough and Clean Hockey Program was found to help 2 of the 3 players enhance their ability to manage their emotions and decrease their aggressive behaviour.

\section{Interpretation}

In our review of the literature, we found that interventions based on rule changes showed the greatest likelihood of making ice hockey safer for youth. The introduction of the Fair Play Program in several Canadian and American ice hockey leagues has succeeded in reducing penalties; however, only 1 of the 3 studies of the program that we reviewed evaluated injury rates, and it showed a decline. ${ }^{21}$ Educational and psychosocial approaches were found to reduce aggressionrelated high-risk behaviours. Although existing studies of these approaches lacked the power to show reductions in injury rates, these interventions show promise.

Rule changes essentially alter the culture of a sport and clearly define acceptable behaviour for all stakeholders (players, coaches, parents and officials) simultaneously. Although educational interventions, such as the Smart Hockey video, can do this to a certain extent, their effectiveness depends on the involvement and simultaneous change in attitudes and behaviour of all stakeholders. For this involvement and change to occur, educational interventions need to be implemented consistently, associated with an intrinsic reward for the change and have widespread universal application. Such an effect occurred at the New Zealand Rugby Union: when rule changes were implemented along with mandatory nationwide educational programs for injury prevention at all levels, the number of neurologic injuries decreased significantly. ${ }^{38}$ More research is needed regarding mandatory rule changes combined with welldesigned educational interventions implemented at a national level.

Introducing the Fair Play Program in conjunction with educational interventions and enforced rules holds promise in reducing injuries related to aggressive behaviour. Critics of the Fair Play Program's practice of having a pre-established limit of team penalties per game argue that it may encourage teams to believe they are entitled to fill their penalty quotas and that it may limit the number of penalties referees call in high-stakes games. ${ }^{6}$ Removing quotas from the Fair Play Program and introducing stricter penalties for high-risk behaviours (e.g., hits to the head and bodychecking from behind), with a loss of points in the overall standings, may also improve the effectiveness of such systems. ${ }^{39}$ The Fair Play Program is already an accepted part of a minority of hockey organizations, so it could be a means by which to ultimately alter hockey culture.

A change toward different rules and their strict enforcement combined with universal education, structural changes in hockey governance, financial and other incentives for safe play and disincentives for unsafe play holds promise for curbing aggression-related injury.

\section{Limitations}

Most of the studies we reviewed were retrospective in nature. Although attempts were made in some studies to control for confounding factors, this is difficult to accomplish without randomization. The cardinal issues associated with selection bias, information bias and confounding with case-control and cohort studies need to be carefully considered. Randomization is a key to addressing these limitations in future studies of the effects of interventions that attempt to reduce aggression-related hockey injuries.

Variability in outcomes was another limitation. Some studies reported on penalty minutes, others measured injury reduction, and some reported on both. None of the studies assessed outcomes such as attrition from the sport or any positive aspects of aggression. The studies of educational and psychosocial interventions generally had smaller samples and were not designed to measure injury reduction.

Feasibility was not specifically addressed in any of the studies. However, studies that evaluated rule changes reported that the implementation of rule changes was achieved across large numbers of 
players. Cognitive behavioural approaches are time and resource intensive and likely of limited widespread acceptability. Experience from rugby has shown that educational approaches are in between these extremes but that universal nationwide implementation is possible. ${ }^{38}$ None of the studies assessed the cost-effectiveness of interventions - a characteristic closely associated with feasibility. Use of computer technology in future interventions, for example through the $\mathrm{Web}^{40}$ and smartphone applications, could make widespread implementation more cost-effective and feasible.

We were unable to identify any interventions based on economic incentives or disincentives, such as changes in fines, insurance premiums or salaries. A complete assessment of how to make ice hockey safer should include implementation and evaluation of such interventions.

All of the studies included in our review were from North America. Future research should also come from other countries.

Finally, we did not identify studies of legislative changes. However, research into bicycle safety has shown that such changes have the potential to alter behaviour and reduce injury rates. ${ }^{41}$

\section{Conclusion}

Several studies included in our review showed that changes to rules to limit the exposure of youth to bodychecking were associated with reduced rates of injury among ice hockey players. Other interventions, including the Fair Play Program, educational interventions and cognitive behavioural modification, had positive effects on reducing aggressive acts; however, more research is needed to determine whether these approaches reduce injury rates on their own. Well-designed multifaceted strategies that combine such approaches hold promise and should be the topic of future research.

\section{References}

1. International Symposium on Concussion in Sport. Abstracts. $\mathrm{Br} J$ Sports Med 2001;35:367-77.

2. Echlin PS, Tator $\mathrm{CH}$, Cusimano MD, et al. A prospective study of physician-observed concussions during junior ice hockey: implications for incidence rates. Neurosurg Focus 2010;29:E4

3. Marchie A, Cusimano MD. Bodychecking and concussions in ice hockey: Should our youth pay the price? CMAJ 2003;169: 124-8.

4. Emery CA, Meeuwisse WH. Injury rates, risk factors, and mechanisms of injury in minor hockey. Am J Sports Med 2006;34: 1960-9.

5. Roberts WO, Brust JD, Leonard B. Youth ice hockey tournament injuries: rates and patterns compared to season play. Med Sci Sports Exerc 1999;31:46-51.

6. Stuart MJ, Colbenson CML, Kronebusch SP. A psychosocial perspective of aggression in ice hockey. In: Ashare AB, editor. Safety in ice hockey: third volume. West Conshohocken (PA): American Society for Testing and Materials; 2000. p. 199-219.

7. Brust JD, Leonard BJ, Pheley A, et al. Children's ice hockey injuries. Am J Dis Child 1992;146:741-7.

8. Gerberich SG, Finke R, Madden M, et al. An epidemiological study of high school ice hockey injuries. Childs Nerv Syst 1987;3: 59-64.
9. Emery CA. Risk factors for injury in child and adolescent sport: a systematic review of the literature. Clin J Sport Med 2003;13: 256-68.

10. MacKay M, Scanlan A, Olsen L, et al. Looking for the evidence: a systematic review of prevention strategies addressing sport and recreational injury among children and youth. J Sci Med Sport 2004; 7:58-73.

11. McIntosh AS, McCrory P. Preventing head and neck injury. $\mathrm{Br} J$ Sports Med 2005;39:314-8.

12. Warsh JM, Constantin SA, Howard A, et al. A systematic review of the association between body checking and injury in youth ice hockey. Clin J Sport Med 2009;19:134-44.

13. Castaldi CR, Hoerner EF, editors. Safety in ice hockey. West Conshohocken (PA): American Society for Testing and Materials; 1989.

14. Castaldi CR, Bishop PJ, Hoerner EF, editors. Safety in ice hockey: second volume. West Conshohocken (PA): American Society for Testing and Materials; 1993.

15. Ashare $\mathrm{AB}$, editor. Safety in ice hockey: third volume. West Conshohocken (PA): American Society for Testing and Materials; 2000.

16. Pearsall DJ, Ashare AB, editors. Safety in ice hockey: fourth volume. West Conshohocken (PA): American Society for Testing and Materials; 2004.

17. Greenwald R, Ashare AB, editors. Safety in ice hockey: fifth volume. West Conshohocken (PA): American Society for Testing and Materials; 2010.

18. Downs SH, Black N. The feasibility of creating a checklist for the assessment of the methodological quality both of randomised and non-randomised studies of health care interventions. J Epidemiol Community Health 1998;52:377-84.

19. Regnier G, Boileau R, Marcotte G, et al. Effects of body checking in the Pee-Wee (12 and 13) years old division in the province of Quebec. In: Castaldi CR, Hoerner EF, editors. Safety in ice hockey. West Conshohocken (PA): American Society for Testing and Materials; 1989. p. 84-103.

20. Marcotte G, Simard D. Fair-play: an approach to hockey for the 1990s. In: Castaldi CR, Bishop PJ, Hoerner EF, editors. Safety in ice hockey: second volume. West Conshohocken (PA): American Society for Testing and Materials; 1993. p. 103-7.

21. Roberts WO, Brust JD, Leonard B, et al. Fair-play rules and injury reduction in ice hockey. Arch Pediatr Adolesc Med 1996; 150:140-5.

22. Watson RC, Singer CD, Sproule JR. Checking from behind in ice hockey: a study of injury and penalty data in the Ontario University Athletic Association Hockey League. Clin J Sport Med 1996;6:108-11.

23. Brunelle JP, Goulet C, Arguin H. Promoting respect for the rules and injury prevention in ice hockey: evaluation of the fair-play program. J Sci Med Sport 2005;8:294-304.

24. Macpherson A, Rothman L, Howard A. Body-checking rules and childhood injuries in ice hockey [published erratum in Pediatrics 2006;117:2334-6]. Pediatrics 2006;117:e143-7.

25. Hagel BE, Marko J, Dryden D, et al. Effect of bodychecking on injury rates among minor ice hockey players. CMAJ 2006;175: 155-60.

26. Gee CJ, Potwarka L. The impact of introducing legal punishment on the frequency of aggressive behaviour in professional ice hockey: using the Todd Bertuzzi incident as an ecological case study. Online J Sports Psychol 2007;9:15-30.

27. Emery CA, McKay CD, Campbell TS, et al. Examining attitudes toward body checking, levels of emotional empathy and levels of aggression in body checking and non-body checking youth hockey leagues. Clin J Sport Med 2009;19:207-15.

28. Emery CA, Kang J, Shrier I, et al. Risk of injury associated with body checking among youth ice hockey players. JAMA 2010;303:2265-72.

29. Kukaswadia A, Warsh J, Mihalik JP, et al. Effects of changing body-checking rules on rates of injury in minor hockey. Pediatrics 2010;125:735-41.

30. Cusimano MD, Taback NA, McFaull SR, et al. Effect of bodychecking on rate of injuries among minor hockey players. Open Med 2011;5:e57-64.

31. Emery C, Kang J, Shrier I, et al. Risk of injury associated with bodychecking experience among youth hockey players. CMAJ 2011;183:1249-56.

32. Trudel P, Bernard D, Boileau R, et al. Effects of an intervention strategy on body checking, penalties, and injuries in ice hockey. In: Ashare AB, editor. Safety in ice hockey: third volume. West Conshohocken (PA): American Society for Testing and Materials; 2000. p. 237-49.

33. Cook DJ, Cusimano MD, Tator $\mathrm{CH}$, et al. Evaluation of the ThinkFirst Canada, Smart Hockey, brain and spinal cord injury prevention video. Inj Prev 2003;9:361-6. 
34. Smith AM, Jorgenson M, Sorenson MC, et al. Hockey Education Program (HEP): a statewide measure of fair play, skil development, and coaching excellence. J ASTM Int 2009;6: $1-14$.

35. Mattesi M. The effects of an aggression-management training intervention program on controlling ice hockey player penalty minutes. Morgantown (WV): West Virginia University; 2002.

36. Lauer L, Paiement C. The Playing Tough and Clean Hockey Program. Sport Psychol 2009;23:543-61.

37. Vaz E. The professionalization of young hockey players. Lincoln (NB): University of Nebraska Press; 1982.

38. Cusimano MD, Nassiri F, Chang Y. The effectiveness of interventions to reduce neurological injuries in rugby union: a systematic review. Neurosurgery 2010;67:1404-18.

39. Sheldon JP, Aimar CM. The role aggression plays in successful and unsuccessful ice hockey behaviors. Res Q Exerc Sport 2001 72:304-9.

40. Montelpare W, McPherson M, Sutherland M, et al. Introduction to the Play It Cool Safe Hockey Program. Int J Sports Sci Coaching 2010;5:61-73.

41. McPherson A, Spinks A. Bicycle helmet legislation for the uptake of helmet use and prevention of head injuries [review]. Cochrane Database Syst Rev 2008;(3):CD005401.
Affiliations: From the Division of Neurosurgery, and the Injury Prevention Research Office, Keenan Research Centre, St. Michael's Hospital, University of Toronto, Toronto, Ont.

Contributors: Michael Cusimano conceived of the study, and Sofia Nastis and Laura Zuccaro performed the literature search. All of the authors performed the critical appraisal and analysis of findings, wrote and revised the manuscript and approved the final version submitted for publication.

Funding: This study was funded by a Canadian Institutes of Health Research Strategic Team Grant in Applied Injury Research in partnership with the Ontario Neurotrauma Foundation (grant no. TIR-103946). The opinions are those of the authors and not of the funding agencies.

Acknowledgements: The authors acknowledge Dr. David Lightfoot for his assistance in searching the literature, and Sharon Nancekivell and Shudong Zhang for their editorial assistance in preparing the manuscript for submission.

Michael Cusimano leads the Canadian Brain Injury and Violence Research Team. 